\title{
Comparative Study of the Conventional and Optical Communication Analog Fire Detector Signal Attenuations with Various Number of Fire Detectors
}

\author{
Ha-Sung Kong ${ }^{1}$, Jong-Seog Yang ${ }^{2}$ and Kwang-Sun Kang ${ }^{3 *}$ \\ ${ }^{1}$ Department of Fire Safety, Kyungil University, 50 Gamasilgil \\ Haynagup Gyeongsan Gyeongbuk 712-701, South Korea \\ ${ }^{2}$ Hyundai Infra Core, Inc., 52, Chungmin-ro, Songpa-gu, Seoul, 138-961 South \\ Korea (B-dong, 904-ho, Garden 5WK, Munjung-Dong) \\ ${ }^{3 *}$ Department of New and Renewable Energy, Kyungil University, 50 Gamasilgil \\ Haynagup Gyeongsan Gyeongbuk 712-701, South Korea
}

\begin{abstract}
Comparative investigations of the conventional analog and optical communication analog fire detector signal attenuations with various numbers of fire detectors were performed in this research. The conventional fire detector signals with 1, 2, 16 and 32 fire detectors were 4.5, 4.0, 2.2 and $0.8 \mathrm{~V}$, respectively. The fire detector signals were drastically decreased with the increase of the number of fire detectors. However, the optical communication fire detector signals were not changed with increasing the number of fire detectors. Therefore, optical communication fire detector system is a promising fire detection system for eliminating the false alarms.
\end{abstract}

Keywords: conventional analog fire detector, optical communication analog fire detector, signal attenuation, false alarm

\section{Introduction}

The occurrence of a fire can be signaled to people thanks to an automatic fire detection system, which automatically detects heat, smoke, ultraviolet light, infrared light or flame with heat detector, smoke detector, ultraviolet sensor, infrared sensor or flame sensor. Automatic fire detection system can be installed only for fire detection or for working together with fire-fighting equipment [1].

Automatic fire detection systems play an important role in early fire detections. However, because of the frequent occurrence of false alarms and nuisance alarms, the fire detections systems are often switched off on purpose and therefore cannot fill their role in case of fire. These nuisance alarms are caused by the sensitivity of fire alarm systems to communication noise. This is why it is important to measure its impact [2].

Until now, there are many researches related to automatic fire detection system with optical communication method, such as a study for field application and stabilization of rail breakage detection system using optical communication system by Tae-Geon Kim, Si-Hang Cho, Su-Young Jeon [3]; a study for unified communication system design and implementation for inside and outside fleet communication by Chai-Dong Lee, Woo-Seop Sin, Chan-Gon Cho Seok-Chan Kim [4]; investigation for the development of automatic alignment system for optical communication fiber array block by Myung-Ho Kim, KiYoung Lee, Gie-Pung Kim, Sun-Seop Park [5]; investigation for the development of the auto test equipment using optical communication by Gyeong-Jin Cho [6]; a study for the development of contact block relay using optical communication by Hyeon-Gi Jeong, Tae-Pung An, Byoung-Hyeong Kim, Gyeong-Gu Lee [7]; investigation for the development and field test of the occlusion information transfer device using optical communication by Byeong-Uk Kang, Si-Bin Lee, Seung-Cheul Lss, Hyo-Suk Sim [8]; 
investigation of processing and interpretation for the aspherical lens mold core using optical communication by Jae-Kuk Oh [9]; a study for the mathematical approximation equation signal distortion for optimally color dispersion-compensated optical communication system by Sung-Man Kim [10]; a study for PLC optical communication device implementation technology in RTR process by Jung-Hoon Kim, So-Hee Kim, HoJoo Kang, Sang-Guk Joo, Tae-Hoo Lee, Myeong-Young Jeong [11]. Development of optical communication for space craft and near-terrestrial space were investigated [12]. The investigation of the fire detection system with optical communication does not exist. We report in this paper for the fire detector signal attenuation with various numbers of fire detectors for the conventional RS-485 analog fire detector and optical communication analog fire detector to eliminate the false alarm.

\section{Experiment}

\subsection{Equipment Design and Fabrication}

The analog detector of the optical communication is comprised with control unit, input unit, power supply, sensor part and communication port. The control unit uses a 32 bit microprocessor (Nuvoton-054, Cortex-M0) and dip switch. The input unit was composed with an address set switch with LED. The power supply unit has regulator (LM2576-12) and linear regulator (kia7805, IP1117). The sensor can detect smoke and measure the temperature with fast a responding NTC-type thermistor (LNTK103F). Figure 1 shows the system block diagram. The circuit and picture of the system is shown in Figure 2.

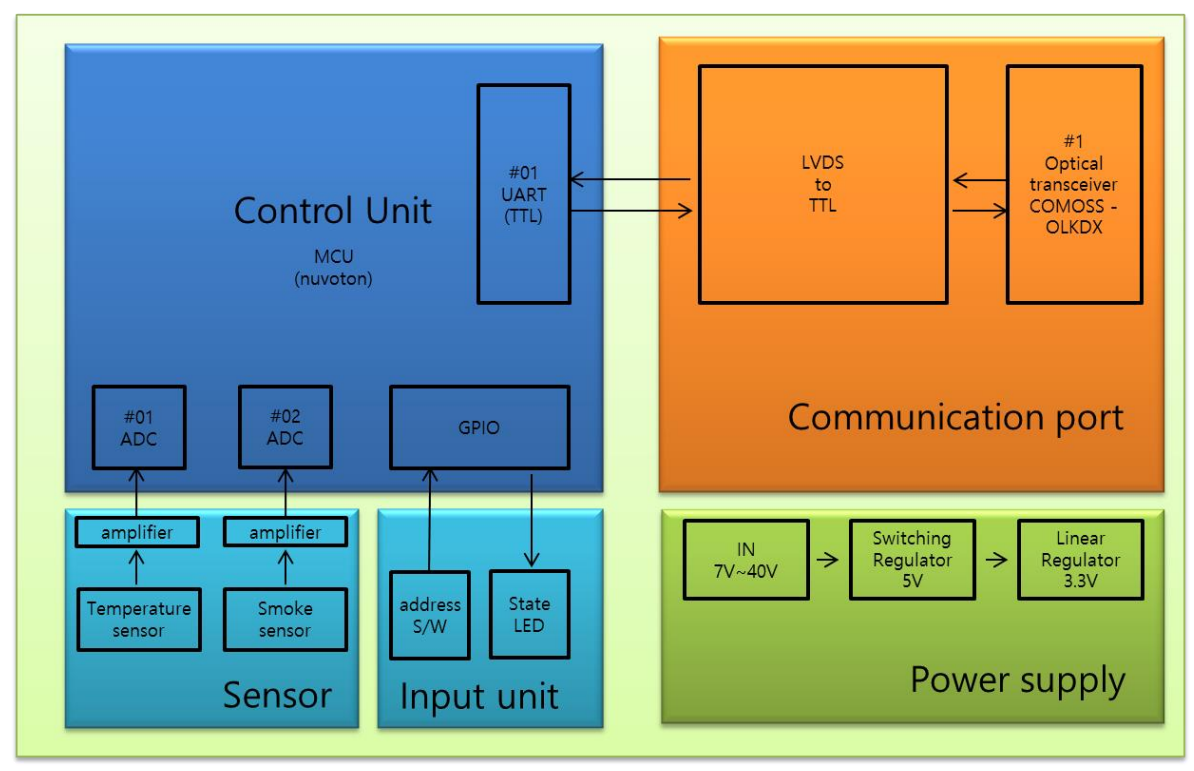

Figure 1. Block Diagram of the System 

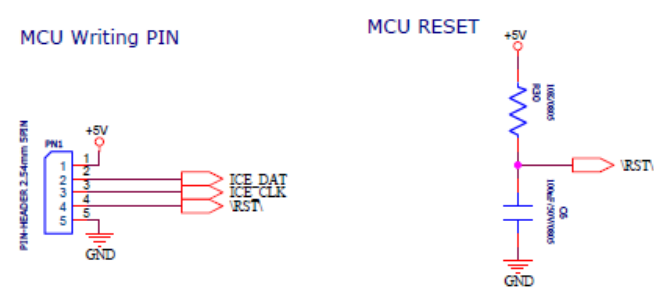

MCU CRYSTAL

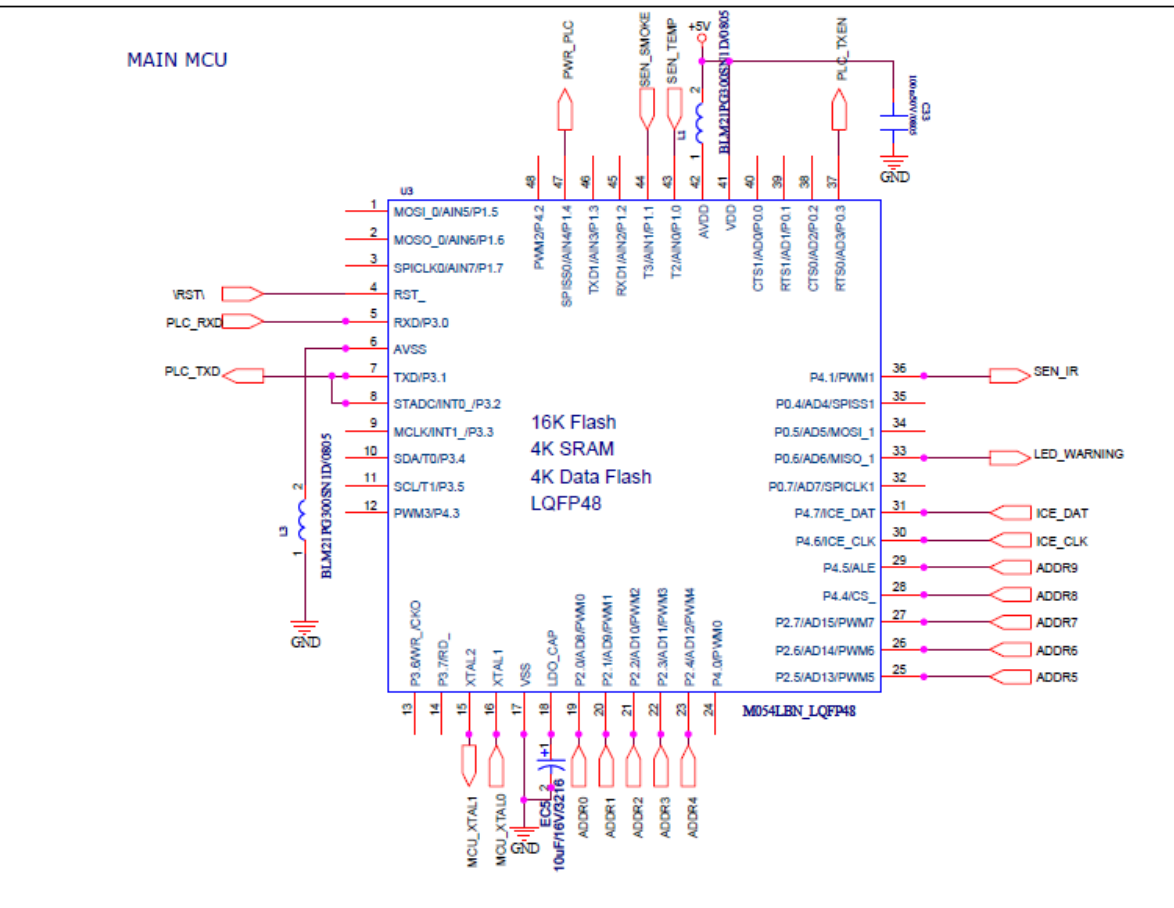

(a) Circuit of the Control Unit

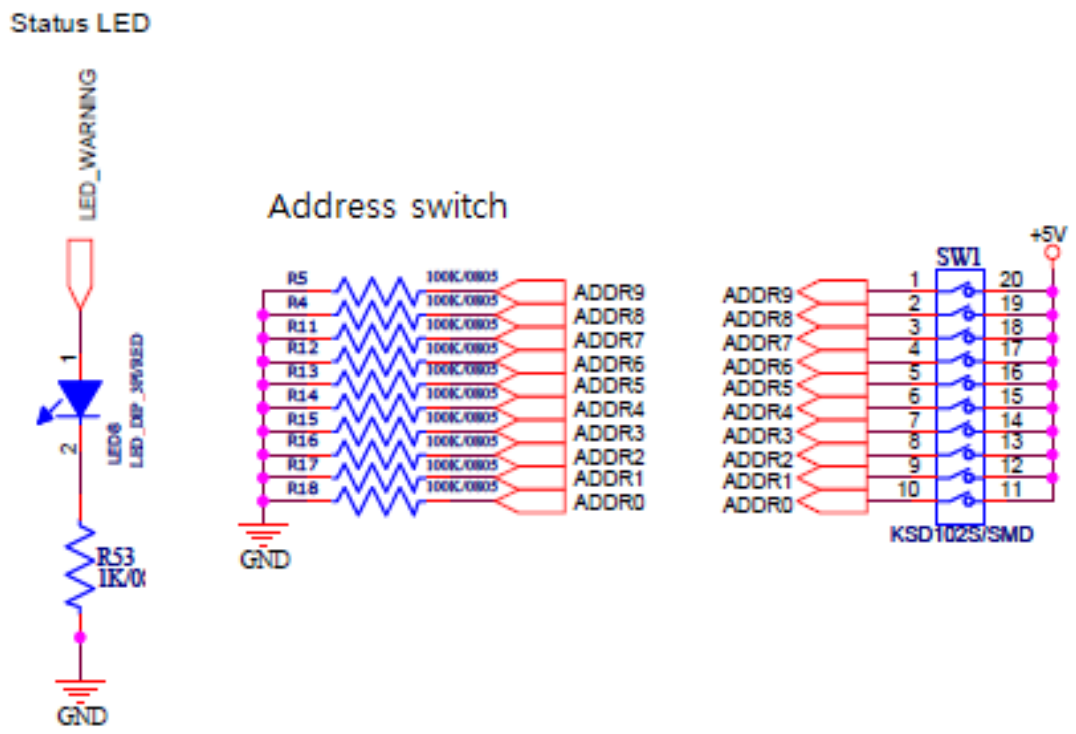

(b) Circuit of the Input Unit 

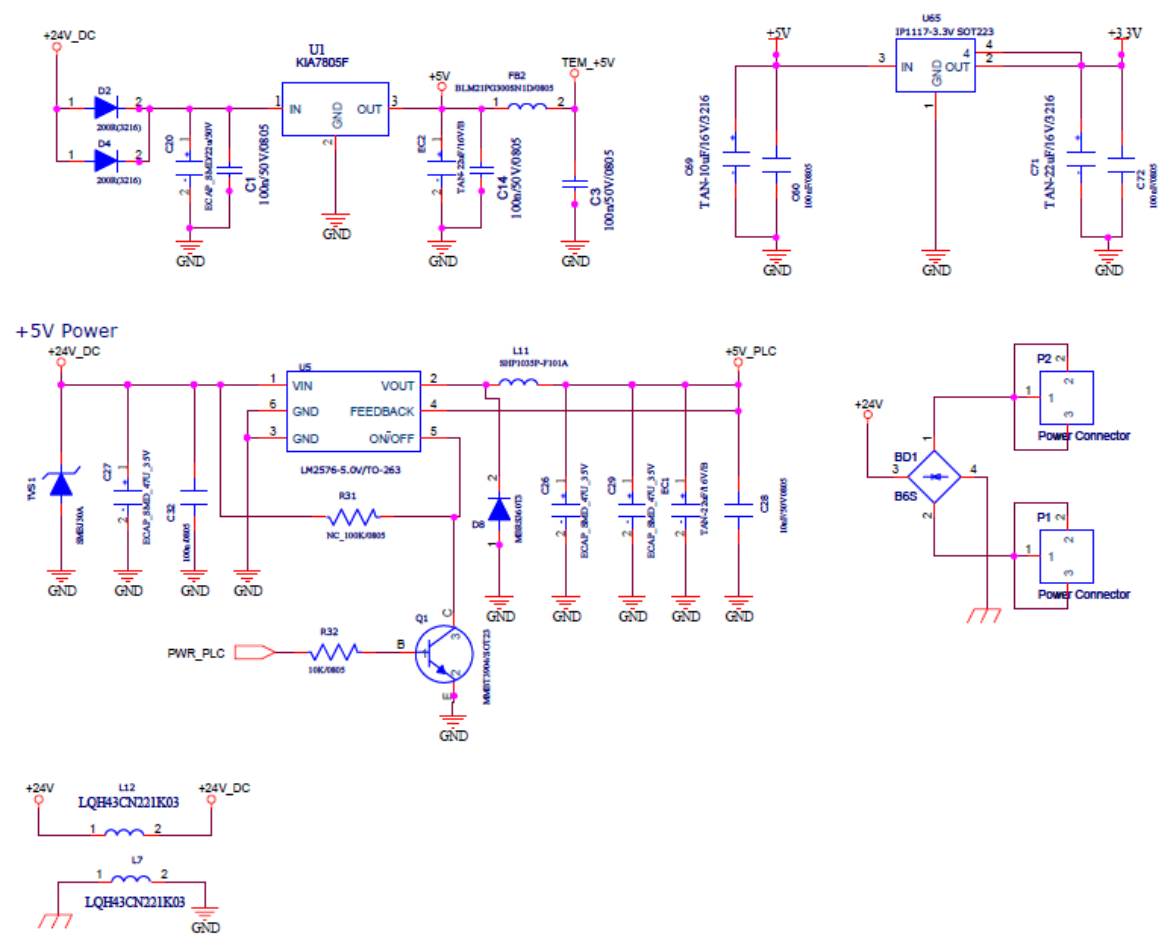

(c) Circuit Of The Power Supply

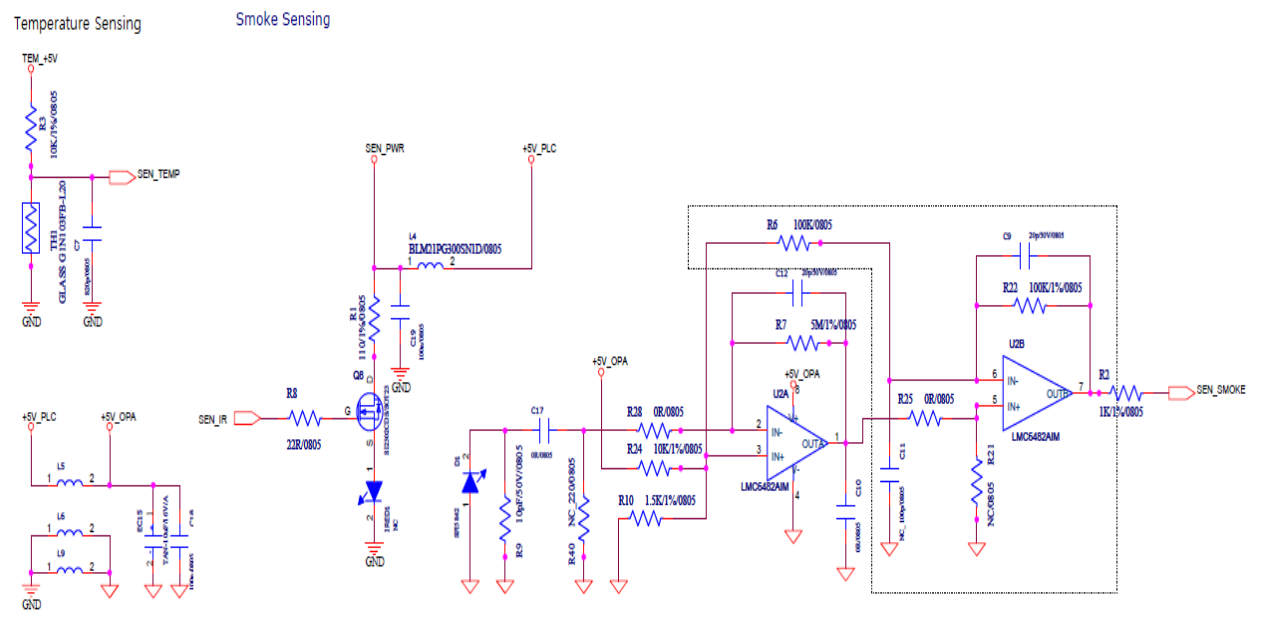

(d) Circuit of the Sensor Part 

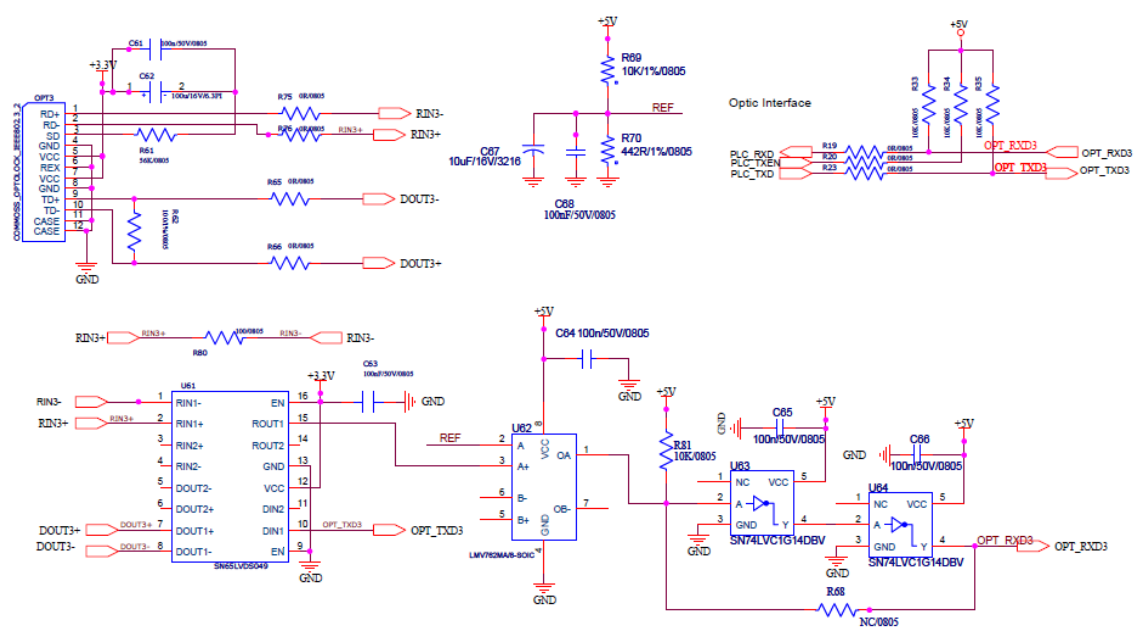

(e) Circuit of the Communication Part

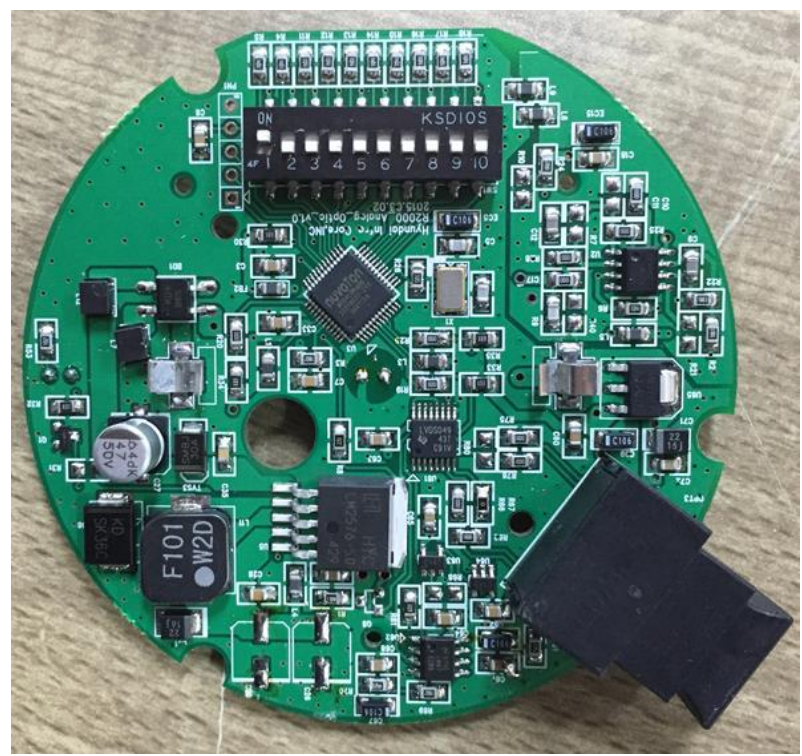

(f) Picture of the System

Figure 2. Picture of the System and System Circuit

\subsection{Experiment Setup}

Figure 3(a) and 3(b) show the conventional analog fire detector and optical communication analog fire detector, respectively. In this experiment, 32 conventional analog fire detectors and 32 optical communication analog fire detectors are prepared. 


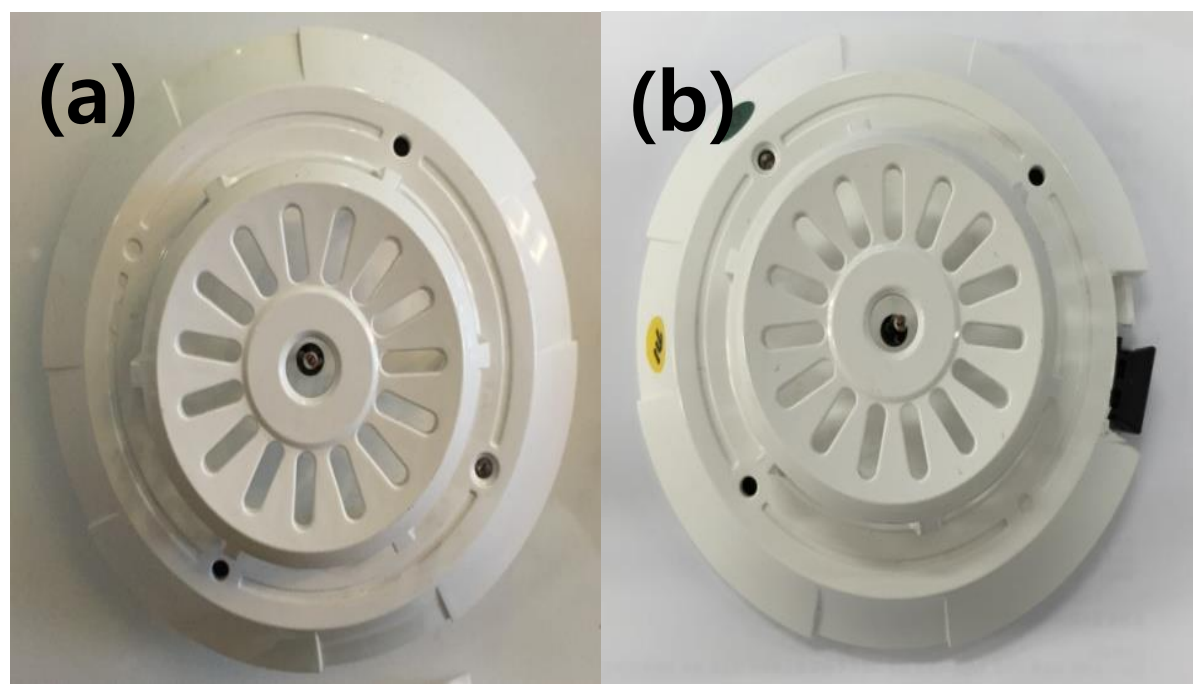

Figure 3. (A) Conventional Analog Fire Detector and (B) Optical Communication Analog Fire Detector (Manufacturer; Hyundai Infra Core, Inc.)

Figure 4 shows the shape of the oscilloscope for measuring the signal attenuation with increasing the communication load. Table 1 shows the oscilloscope specification.

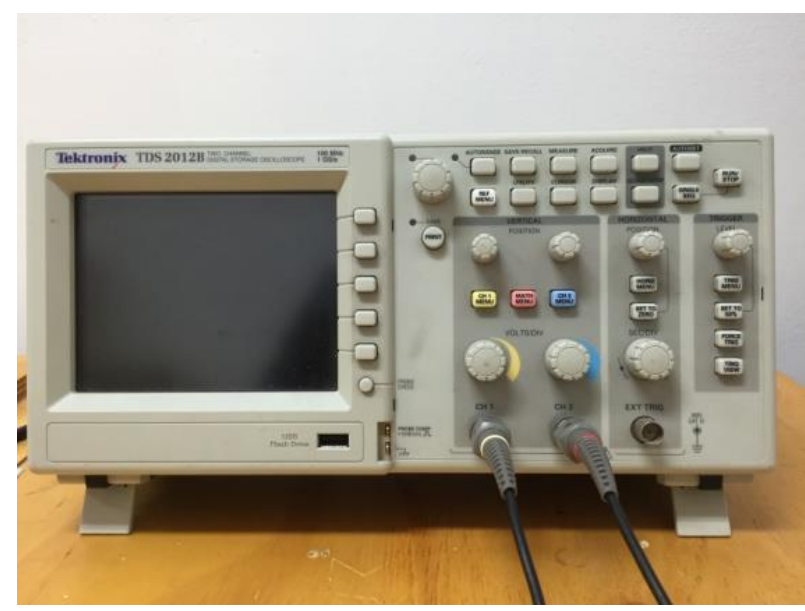

Figure 4. The Shape of the Oscilloscope

Table 1. Specification of the Oscilloscope

\begin{tabular}{|l|l|}
\hline Items & Explanation \\
\hline Name & Digital Oscilloscope \\
\hline Model name & TDS 2012B \\
\hline Analog & 2Channels \\
\hline Max. sampling rate & $1.0 \mathrm{GS} / \mathrm{s}$ Real time \\
\hline $\begin{array}{l}\text { Analog Frequency } \\
\text { Bandwidth }\end{array}$ & $100 \mathrm{MHz}$ Bandwidths \\
\hline Max. Record length & $2.5 \mathrm{~kW} / \mathrm{Ch}$. \\
\hline manufacturer & Tektronix \\
\hline
\end{tabular}


Conventional analog 1,2, 16 and 32 fire detectors and optical communication analog 1, 2, 16 and 32 fire detectors were connected to the code transmitter and oscilloscope as shown in Figure 3.
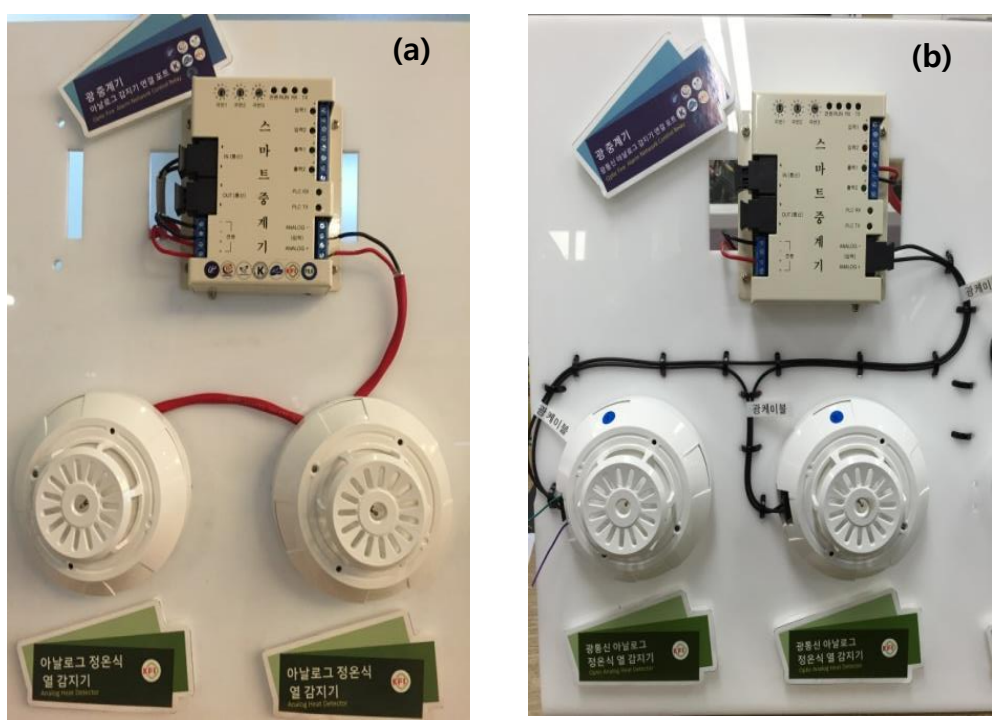

Figure 5. (A) Connection of the Conventional Analog Fire Detector and (B) Optical Communication Analog Fire Detector

\subsection{Experimental Method}

The experimental procedures were listed below. (1) preparation of 32 conventional analog fire detector and 32 optical communication analog fire detector (4) connection of the power cable to the code transmitter (5) connection the communication cable to the 1,2, 16 and 32 fire detectors (6) supply the DC24V power to the master code transmitter (7) supply DC24V to the each code transmitter (8) set the oscilloscope with the following table 2 and connect the probe to the communication input.

Table 2. Set Condition of the Oscilloscope

\begin{tabular}{|l|l|l|}
\hline Kind of detectors & Horizontal axis (speed) & Vertical axis (Voltage) \\
\hline $\begin{array}{l}\text { Conventional analog } \\
\text { fire detector }\end{array}$ & $25 \mathrm{us} / \mathrm{div}$ & $2 \mathrm{~V} / \mathrm{div}$ \\
\hline $\begin{array}{l}\text { Optical } \\
\text { communication } \\
\text { analog fire detector }\end{array}$ & $250 \mathrm{us} / \mathrm{div}$ & $2 \mathrm{~V} / \mathrm{div}$ \\
\hline
\end{tabular}

\section{Results and Discussion}

\subsection{The Signal Waveform with Various Communication Loads}

Table 3 shows the signal attenuation depending on the communication load for conventional analog fire detectors and optical communication analog fire detectors. In this 
experiment 1,2, 16 and 32 fire detectors were connected to the code transmitter and oscilloscope to detect the signal attenuation.

Table 3. Signal Attenuation Depending on the Fire Detector Communication Loads

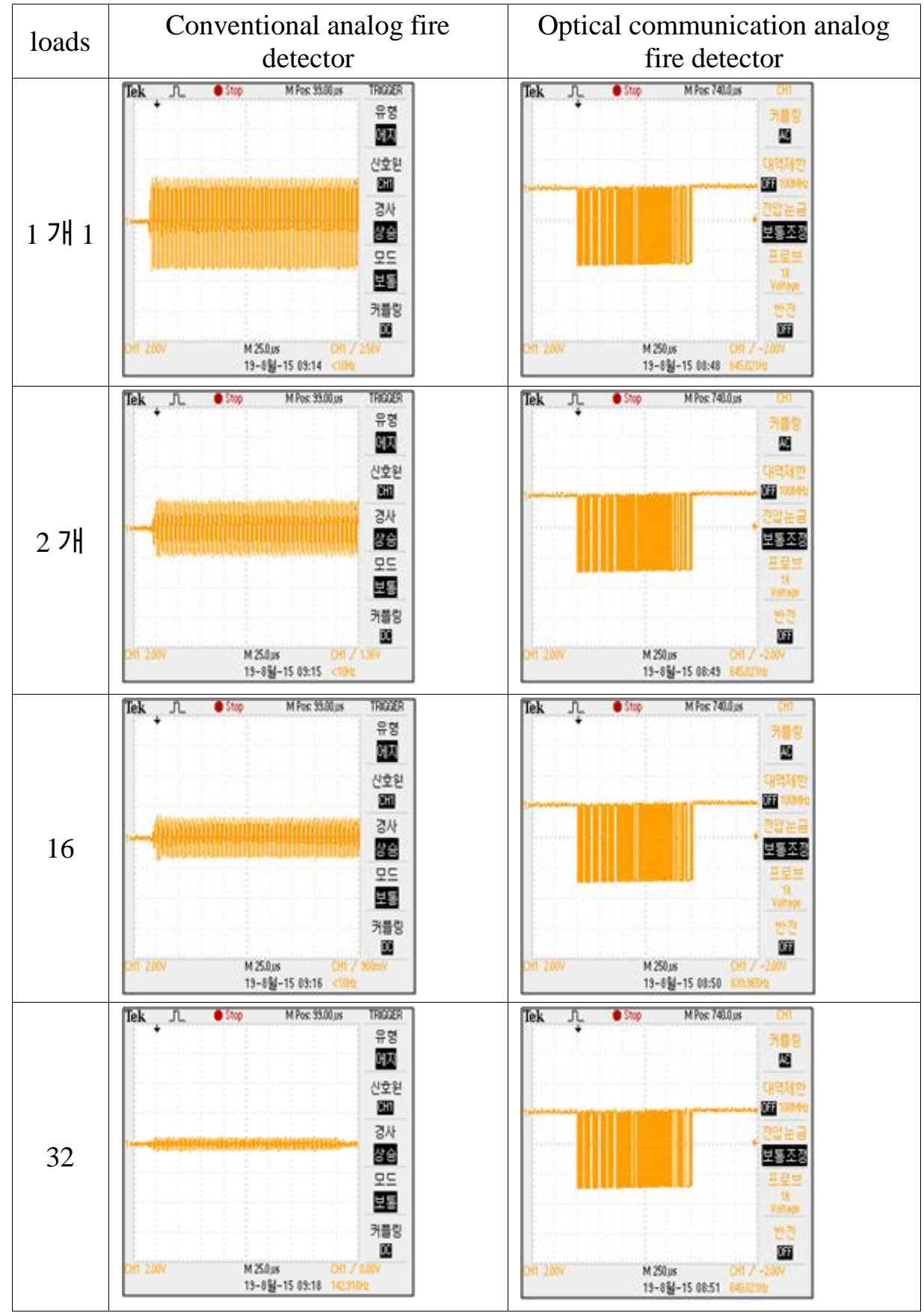

\subsection{Test Results}

The conventional analog signals were respectively $4.5,4.0,2.2$ and $0.8 \mathrm{~V}$ for $1,2,16$ and 32 fire detector loads. The analog signals were drastically reduced by increasing the number of fire detectors connected to one code transmitter when connected with $\mathrm{R}$. However, the analog signals were not reduced with the increase the number of optical 
communication analog fire detector. Table 4 shows the conventional and optical communication analog fire detector signals with different number of fire detectors.

Table 4. Comparison of Code Transmitter Signals Connected Various Number of Conventional and Optical Communication Analog Fire Detectors

\begin{tabular}{|c|c|c|}
\hline $\begin{array}{l}\text { Number } \\
\text { of fire } \\
\text { detectors }\end{array}$ & $\begin{array}{c}\text { Conventional analog fire } \\
\text { detectors }\end{array}$ & $\begin{array}{l}\text { Optical communication analog } \\
\text { fire detectors }\end{array}$ \\
\hline 1 & $\begin{array}{c}\text { Communication signal level; } \\
4.5 \mathrm{~V}\end{array}$ & \multirow{4}{*}{$\begin{array}{l}\text { No change of the } \\
\text { communication signal level }\end{array}$} \\
\hline 2 & $\begin{array}{l}\text { Communication signal level; } \\
4.0 \mathrm{~V}\end{array}$ & \\
\hline 16 & $\begin{array}{l}\text { Communication signal level; } \\
2.2 \mathrm{~V}\end{array}$ & \\
\hline 32 & $\begin{array}{c}\text { Communication signal } \\
\text { level; } 0.8 \mathrm{~V}\end{array}$ & \\
\hline
\end{tabular}

\section{Conclusion}

This research focused on the signal attenuation with various numbers of conventional and optical communication analog fire detectors connected to one code transmitter. We obtained the following results.

1) The code transmitter signals for the conventional analog fire detectors were 4.5, 4.0, 2.2 and $0.8 \mathrm{~V}$ for $1,2,16$ and 32 fire detectors, respectively. The code transmitter signals were drastically reduced with increasing the number of fire detectors.

2) However, the code transmitter signals for optical communication analog fire detectors were not changed by increasing the number of fire detectors.

Therefore, large number of the optical communication analog fire detectors can be used to one code transmitter without false alarm.

\section{References}

[1] S.H. Jang, "Dictionary for English-Korean fire safetywords", Hanjin Printing, vol. 371, (2000).

[2] T.D. Kim, "A Study on the improvement of False Fire Alarm in Auto Fire Detect SyStem", Seoul City University, Master Thesis, (2005).

[3] T.G. Kim, S.H. Choi, G.B. Cha and S.Y. Chung, "A Study on the Application on Site and Stability of Broken Rail Detection Equipment using the Optical Method Journal korean Society", Urban Railway, vol. 1, no. 39, (2013).

[4] C.D. Lee, W.S. Shin, C.G. Jo and S.C. Kim, "Design and Implementation of the Intefrated Communication System based on The Optical Network for The Naval Shipment", Journal Institute of Electronics Engineering Korea, vol. 47, no. 733, (2010).

[5] M.H. Kim, G.Y. Lee, G.P. Kim and S.S. Park, "Development of auto array system for FAB (Fiber array block) of Optical Communication", Proceeding Fall Ann. Conference Korean Society of Manufacturing Technical Engineering, vol. 175, (2011).

[6] K.J. Choi, "A Study on the ATE (Auto Test Equipment) Development for Military Optic Communication", Procedure Fall Ann. Conference Korean Institute of Committee Information Science, vol. 450, (2012).

[7] H.K. Jung, T.P. An, B.H. Kim and K.G. Lee, "A Study on the Development of Inter Iinked Breaking Relay Using Optical Communication”, Proceeding Fall Ann. Conference Korean Society Railway, vol. 1364, (2012).

[8] B.W. Kang, S.B. Lee, S.C. Lee and H.S. Sim, "A Development of the Block Information Transmission Unit Based On Optical Communication and Practical Test”, Proceeding Fall Ann. Conference Korean Institute of Communication and Information Science, vol. 1063, (2014). 
[9] J.K. Oh, "A Study on Analysis and Maching of Mold Core For Optical Communication Aspheric Lens", Journal Korean Society Mechanical Technology, vol. 15, no. 305, (2013).

[10] S.M. Kim, "Analytic Expression of the Signal Distortion in Dixpersion-Managed Optical Transmission", Journal Korea Institute of Electronic Committee Science, vol. 8, no. 1235, (2013).

[11] J.H. Kim, S.H. Kim, H.J. Kang, K. Cho, T.H. Lee and M.Y. Jeong, "Implementation of PLC Edvice by Roll to Roll Process", Journal Korean Soceity Precision Engineer, vol. 31, no. 469, (2014).

[12] B.G. Boone, J.R. Bruzzi, B.E. Kluga, W.P. Millard, K.B. Fielhauer, D.D. Duncan, D.V. Hahn, C.W. Drabenstadt, D.E. Mauere and R.S. Bokulic, "Optical Communications Development for Spacecraft Applications”, Johns Hopkins APL Technical Digest, vol. 25, (2004), pp. 306-315. 